Décadrages Décadrages

cinéma, à travers champs Cinéma, à travers champs

$7 \mid 2006$

Stephen Dwoskin

\title{
Entre burlesque et tragique : Lenz, ou la création au quotidien
}

\section{Alain Boillat}

\section{(2) OpenEdition}

1 Journals

\section{Édition électronique}

URL : https://journals.openedition.org/decadrages/453

DOI : $10.4000 /$ decadrages. 453

ISSN : 2297-5977

Éditeur

Association Décadrages

\section{Édition imprimée}

Date de publication : 10 avril 2006

Pagination : 102-104

ISBN : 978-29700582-3-6

ISSN : 2235-7823

\section{Référence électronique}

Alain Boillat, «Entre burlesque et tragique : Lenz, ou la création au quotidien », Décadrages [En ligne], 7 | 2006, mis en ligne le 30 janvier 2014, consulté le 03 avril 2022. URL : http://journals.openedition.org/ decadrages/453 ; DOI : https://doi.org/10.4000/decadrages.453

Ce document a été généré automatiquement le 3 avril 2022.

(B) Décadrages 


\title{
Entre burlesque et tragique : Lenz, ou la création au quotidien
}

\author{
Alain Boillat
}

1 La dernière fiction du cinéaste Thomas Imbach, lointainement mais intensément inspirée de la nouvelle inachevée de Georg Büchner qui retrace les souffrances du poète J. M. R. Lenz aux prises avec les démons de la folie, peut être considérée à mon sens comme la réalisation esthétiquement la plus marquante de cette édition des Journées de Soleure. Posant une équivalence entre l'œuvre et la vie d'un auteur, Imbach concilie la représentation de la démence avec un moyen d'expression qui ne peut se passer d'une médiation technologique complexe fonctionnant a priori au détriment d'un élan purement instinctif. Lenz joue en effet sur la "transparence » de la représentation cinématographique qu'il brise en suggérant la présence d'une instance de filmage, tout en ne faisant émerger que ponctuellement cette dimension réflexive ${ }^{1}$. Serrant le protagoniste principal au plus près ${ }^{2}$, la prise de vues semble physiquement mêlée aux actions saugrenues et primesautières de ce dernier, qui prennent souvent l'apparence de happenings : son comportement est le film, et inversement. Projetant de réaliser une adaptation cinématographique de Lenz, le réalisateur interprété par Milan Peschel se confond avec son personnage (au point de lui emprunter son patronyme) et transpose à l'époque contemporaine la vision du monde de l'auteur du Sturm und Drang en la faisant sienne : le biopic dérive vers l'autobiographie (ou l'autofiction). On comprend combien la notion d'adaptation littéraire s'effrite, renouvelée par le portrait d'un inadapté social. Lorsqu'une jeune femme qui se destine à devenir actrice lit à haute voix un extrait de la nouvelle de Büchner, Lenz lui reproche d'avoir oublié une virgule. L'« adaptation » d'Imbach est à la fois aux antipodes d'une reprise " à la virgule près » d'un texte antérieur, et intimement liée au rythme insufflé par la ponctuation, par le souffle du style discontinu de Büchner, sur lequel le montage saccadé du film semble se modeler ${ }^{3}$.

2 Lenz gravite continûment autour du anti-héros éponyme, entraîné dans un mouvement égocentrique. Il fallait donc que l'acteur soit à la hauteur, ce qui est le cas : dans les traits tendus de son visage à la Klaus Kinski - ressemblance accentuée lorsqu'il se 
travestit avec une perruque blonde ${ }^{4}$ - dont le regard à la fois hagard et déterminé semble gagner d'insondables espaces intérieurs, Peschel concentre par moments une agressivité désespérée qui sied parfaitement au personnage. De plus, l'acteur, se pliant apparemment à tous les desiderata quelque peu sadiques du cinéaste (se balader presque nu dans la neige, faire des chutes répétées à ski, marcher dans l'eau glacée, etc. $)^{5}$, exploite sa physionomie digne d'un cartoon et déploie des mouvements dégingandés qui confèrent au film une efficacité burlesque certaine. C'est même l'un des tours de force du film que d'avoir dépassé le pessimisme fondamental de sa source littéraire à travers la représentation en actes de la figure du créateur : les «mises en scène » auquel s'adonne un Lenz souvent emporté par une pulsion régressive ancrent dans des situations concrètes la figuration symbolique d'un tempérament torturé (il «n'a pas froid aux yeux », "se jette tête baissée », etc.). Certes, la socialisation du protagoniste du film se distingue radicalement de l'extrême solitude du Lenz dépeint par Büchner. Alors que, dans la nouvelle, le dramaturge est accueilli par le pasteur Oberlin, le Lenz du film vient rendre une visite inopinée à son fils et à son épouse dont il est séparé, ayant préféré vivre à Berlin plutôt qu'en Suisse. Le récit s'apparente donc plutôt à celui du moyen métrage suisse romand On dirait le Sud (Vincent Pluss, 2002) ${ }^{6}$, mais, là où l'immaturité du père était aussi celle du film, Imbach instaure une «distanciation" permanente d'une riche ambiguïté envers cette figure paternelle totalement irresponsable ${ }^{7}$. La fragilité de ce couple momentanément réconcilié est en outre subtilement rendue, l'actrice Barbara Maurer incarnant avec talent un personnage féminin qui oscille entre une admiration amusée pour l'attitude puérile de Lenz et une crainte profonde envers son imprévisibilité et son inconscience. De la confrontation $\mathrm{du}$ jeu de ces acteurs se dégage une atmosphère de perpétuel déséquilibre qui fonctionne au bénéfice de la description d'un état schizophrénique. Le lien avec autrui permet d'introduire la question du regard posé sur l'attitude de Lenz par des instances diégétiques qui ont pour effet de décupler un exhibitionnisme in fine destiné au spectateur du film.

Dans les «personnages» mentionnés au générique de fin, Thomas Imbach a significativement inclus la "montagne ", c'est-à-dire le Cervin. En s'appuyant sur le texte de Büchner où Lenz est initialement présenté, en plein délire, aux prises avec une tempête de neige, le cinéaste fait un usage original de cet environnement typiquement suisse qu'est la haute montagne. Ce paysage alpin n'est pas offert à une contemplation béate, mais s'affirme comme le lieu du déchaînement de forces naturelles ressenties par le personnage comme une agression. C'est pourquoi les plans sur le Cervin sont brouillés, instables, baignés d'une lumière aveuglante et, dans un bourdonnement sourd, nous montrent un sommet parfois traversé par des traînées blanches, avions filmés en accéléré qui ne sont pas sans évoquer les attentats des deux gratte-ciels. Domestiquée pour les sports d'hiver auxquels Lenz s'adonne avec une joie passagère et secrètement suicidaire, la montagne conserve, comme chez Ramuz, sa part d'hostilité. En alternant ces deux facettes du paysage, Imbach développe une vision forte et contrastée entre l'insouciance superficielle et le tragique foncier qui traverse tout le film. Nous invitant à partager la perception du protagoniste, Lenz épouse les soubresauts chaotiques qui jalonnent son parcours. Dans cette œuvre maîtrisée à tous les stades de sa réalisation par Thomas Imbach, forme et sens se répondent mutuellement dans un maelström envoûtant. 
Lenz (2006). Réal. et scénario : T. Imbach Image : J. Hassler, T. Imbach. Montage : T. Imbach, J. Hassler. Interprétation : M. Peschel, B. Maurer, Production : Bachim Film (Zurich), Pandora Film (Cologne), Schweizer Fernsehen.

\section{NOTES}

1. La réflexivité n'apparaît en fait explicitement qu'à deux reprises : lorsqu'un touriste de passage lit dans un manuscrit de Lenz la description d'une séquence qui correspond à ce que nous avons vu précédemment ; à l'instant du regard complice que Lenz adresse à la caméra après avoir évoqué le tournage du film avec celle qui pourrait en être la productrice, conviée contre son gré à prendre place avec lui dans l'igloo qu'il a bâti.

2. Le mode de captation dont use Imbach ainsi que l'auto-mise en scène du protagoniste évoquent Les Idiots de Lars Von Trier (Idioterne, 1998), cinéaste évoqué par le Lenz du film lors d'une discussion avec un couple de Danois.

3. Le film présente une fin ouverte référée, par l'intermédiaire d'une mention graphique (« So lebte er hin »), à la dernière phrase de la nouvelle inachevée.

4. Si l'on pense instantanément au physique d'Aguirre (Aguirre. Der Zorn Gottes, Werner Herzog, 1972), il faut rappeler que Kinski a interprété le rôle de Woyzeck - personnage angoissé également assailli par des hallucinations - dans l'adaptation cinématographique d'une œuvre écrite, tout comme Lenz, par Georg Büchner (Woyzeck, Werner Herzog, 1979).

5. La réflexivité de Lenz excluant la présence d'Imbach au profit de la figure diégétique d'un cinéaste, la mise en scène s'affiche en fait comme un geste d'autodestruction.

6. A propos de ce film, voir Décadrages, $n^{\circ} 1-2$, pp. 194-202.

7. En ce qui concerne la notion de "distanciation ", notons que la filiation Jakob Lenz-Georg Büchner fut d'importance pour la réflexion brechtienne, le " théâtre épique " s'inscrivant dans une conception anti-aristotélicienne dont ces deux auteurs constituent les principaux représentants germaniques (Brecht réalisa d'ailleurs une adaptation du Hofmeister de Lenz). En utilisant le texte de Büchner sur Lenz comme matrice de son film, Thomas Imbach se réclame implicitement de cette tradition théorique et dramaturgique. 